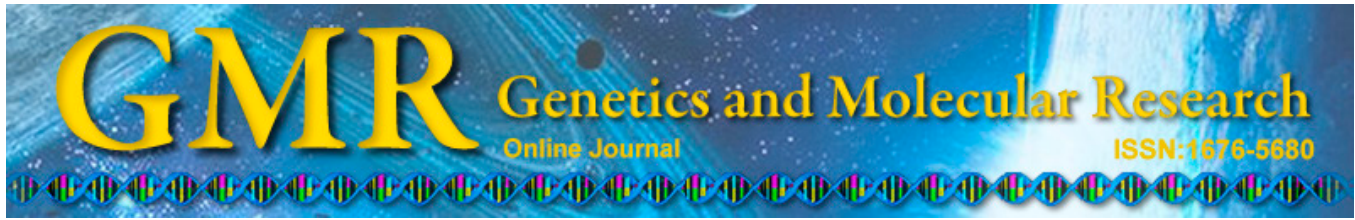

\title{
Pedigrees of infertile Chinese men with Y chromosome microdeletions derived from natural transmission and de novo mutation
}

\author{
L.L. Li ${ }^{1,2}$, Y.Z. Zhu ${ }^{2}$, X.W. Yu ${ }^{1}$, R.X. Wang ${ }^{1}$, Z.M. Hu ${ }^{1,2}$ and R.Z. Liu ${ }^{1}$ \\ ${ }^{1}$ Center for Reproductive Medicine, Center for Prenatal Diagnosis, \\ First Hospital, Jilin University, Changchun, China \\ ${ }^{2}$ Department of Genetic Biology, Norman Bethune Medical School, \\ Jilin University, Changchun, China \\ Corresponding author: R.Z. Liu \\ E-mail:1rz410@126.com
}

Genet. Mol. Res. 14 (1): 1932-1941 (2015)

Received January 7, 2014

Accepted September 12, 2014

Published March 20, 2015

DOI http://dx.doi.org/10.4238/2015.March.20.3

\begin{abstract}
Y chromosome microdeletions can cause male infertility and are classified as natural transmission and de novo mutations. To examine the source of these deletions in Chinese men and to provide a theoretical and laboratory basis for genetic counseling, patients from Northeast China with primary male infertility $(\mathrm{N}=22)$ and their fathers were investigated. Karyotype analysis was performed on peripheral blood lymphocytes using standard G-banding. Multiplex polymerase chain reaction amplification using 18 specific sequence-tagged sites was selected to detect $\mathrm{Y}$ chromosome microdeletions. De novo mutations were observed in 17 father-son pairs, leading to a mutation rate of $77.27 \%(17 / 22)$, while the vertical transmission of Yq AZFc microdeletions was detected in 5 cases of the families investigated $(29.41 \%, 5 / 17)$. There were no statistically significant differences between vertically transmitted and de novo mutations in men with AZFc deletions regarding age, testicular volume, and reproductive hormone
\end{abstract}


levels. Most Y chromosome microdeletions in men from Northeast China are the result of de novo mutations via natural conception, and men with Yq AZFc deletions showed no clear differences between vertical transmission and de novo mutations.

Key words: De novo mutation; Pedigrees; Vertical transmission; $\mathrm{Y}$ chromosome microdeletions

\section{INTRODUCTION}

Microdeletions of the long arm of the human Y chromosome (Yq) represent the main molecular determinants of male infertility and account for approximately $10 \%$ of cases of nonobstructive azoospermia or severe hypospermatogenesis (Stuppia et al., 1998; Ferlin et al., 2007; Gatta et al., 2010). The azoospermia factor (AZF) region is subdivided into 3 non-overlapping hot-spot regions defined as AZFa, AZFb, and AZFc (Briton-Jones and Haines, 2000). The AZFa and AZFb deletions are primarily associated with Sertoli-cell-only syndrome and arrest of spermatogenesis, respectively (Krausz et al., 2000), whereas patients with complete AZFc (b2/b4) deletions may present with a range of phenotypes from azoospermia to severe oligozoospermia (McElreavey et al., 2006). Recently, 3 types of partial AZFc deletions were identified: gr/gr deletion, b2/b3 deletion, and b1/b3 deletion. However, the relationship between these partial AZFc deletions and male infertility remains controversial, and thus further studies of their impact on human spermatogenesis are necessary (McElreavey et al., 2000).

During evolution, homologous recombination involving the elimination of 1 repetitive sequence at the expense of another is thought to account for the random appearance of $d e$ novo AZF microdeletions in men. The fathers or brothers of men with Yq microdeletions typically have non-deleted Y chromosomes and normal sperm counts; these deletions are spontaneous events (Foresta et al., 2001). Therefore, previous studies suggested that deletions are not transmitted to sons unless either in vitro fertilization or intracytoplasmic sperm injection is performed. Intracytoplasmic sperm injection may lead to vertical transmission, expansion, and de novo occurrence of $\mathrm{Y}$ chromosome microdeletions in male fetuses (Rodovalho et al., 2008; Mau Kai et al., 2008). However, data regarding the prevalence of father-to-son natural transmission are limited and it is unknown whether the deletion patient can be fertile based on clinical parameters such as testicular volume and reproductive hormone levels.

In this study, classical AZF microdeletions, including AZFa, AZFb, AZFc, and partial AZFc deletions, were detected in 22 naturally conceived pedigrees to study the source of $Y$ chromosome microdeletions. The aim of the study was to obtain information to generate a theoretical and laboratory basis for genetic counseling of these patients.

\section{MATERIAL AND METHODS}

\section{Subjects}

The study population included 22 pedigrees of 45 family members. The probands were confirmed to be non-obstructive azoospermic (complete absence of sperm), moderate oligozoospermic $(5 \mathrm{million} / \mathrm{mL}<$ sperm concentration $<10 \mathrm{million} / \mathrm{mL}$ ), and severe oligozoospermic (sperm concentration $<5$ million $/ \mathrm{mL}$ ). All cases showed deletions in the AZF region 
and all family members were sampled at the Assisted Reproduction Centers of the First Hospital of Jilin University. Semen analysis for sperm concentration, motility, and morphology was performed following the World Health Organization criteria (World Health Organization, 1999). Family members were interviewed regarding their medical history and a physical examination was conducted. Peripheral blood samples were obtained and stored for cytogenetic detection. All procedures followed Ethical Committee guidelines and all participants signed informed consent.

\section{Karyotype analysis}

Karyotype analysis was performed on peripheral blood lymphocytes using the chromosome G-banding technique. Peripheral blood lymphocytes were cultured in lymphocyte culture medium (Yishengjun; BaiDi Bio-Technology, Guangzhou, China) at $37^{\circ} \mathrm{C}$ for $72 \mathrm{~h}$ and then treated with $50 \mu \mathrm{g} / \mathrm{mL}$ colchicine (Yishengjun, BaiDiBio-Technology) for $1 \mathrm{~h}$. G-banding of metaphase chromosomes was performed by hypotension, fixation, trypsinization, and Giemsa staining. For each individual, a minimum of 30 metaphase cells were counted and at least 5 cells were analyzed. Chromosome abnormalities were described according to the International System for Human Cytogenetic Nomenclature (Shaffer et al., 2009).

\section{Hormonal analysis}

Reproductive hormone levels, including prolactin, luteinizing hormone (LH), plasma follicle-stimulating hormone (FSH), testosterone (T), and estradiol (E2), were measured for all probands and transmitted fathers. Normal reference ranges for men are: prolactin 86-324 $\mu \mathrm{IU} / \mathrm{mL}$; LH 1.7-8.6 mIU/mL; FSH 1.5-12.4 mIU/mL; T 9.9-27.8 nM; and $\mathrm{E}_{2}$ 7.63$42.6 \mathrm{pg} / \mathrm{mL}$.

\section{DNA extraction and polymerase chain reaction (PCR)}

High-molecular-weight genomic DNA was extracted from peripheral blood lymphocytes using a DNA-isolation mini kit (Beijing Tiangen Biotech Co, Ltd. Beijing, China). DNA samples obtained from normal men with proven fertility and normal women were used as positive and negative controls, while a sample containing all reaction components without DNA was used as a blank control.

The $\mathrm{Y}$ chromosome microdeletion analysis of the Yq region involved 2 components. One was to detect the AZFa, AZFb, and AZFc classic microdeletions. Nine sequence-tagged sites (STSs; AZF loci) mapped at intervals 5 and 6 on the long arm of the Y chromosome were used: sY84, sY86 for AZFa; sY127, sY134, and sY143 for AZFb; sY152, sY157, sY254, and sY255 for AZFc. The other was to detect partial AZFc deletions. Nine STSs were used to lock the partial AZFc deletions: sY142, sY1201, sY1191, sY1197, sY1054, sY1206, sY1161, sY1291, and sY1258. A gr/gr deletion was identified by the absence of marker sY1291 and presence of other STSs. The b2/b3 deletion was characterized by the absence of the STS sY1191 and the presence of other STSs. The absence of markers sY1291, sY1191, and sY1197 combined with the presence of others indicated the b1/b3 deletion (Eloualid et al., 2012). In addition, the sex-determining region on the $\mathrm{Y}$ gene and $\mathrm{X} / \mathrm{Y}$ homologous gene pair zinc-finger 
$\mathrm{X}$ and zinc-finger $\mathrm{Y}$ primers were used as positive internal controls.

The screening for AZF classic microdeletions and partial deletions was performed using multiplex PCR, which was carried out in a $20-\mu \mathrm{L}$ reaction system containing: $2 \mu \mathrm{L}$ template genomic DNA (100-200 ng), $1.5 \mathrm{mM} \mathrm{Mg}^{2+}, 800 \mu \mathrm{M}$ dNTPs, $10 \mathrm{pM}$ of each primer, and 2 U Taq polymerase (Beijing Dingguo Biotech, Beijing, China), and free sterile water to a final volume of $20 \mu \mathrm{L}$. The amplification reaction was performed in a programmable thermal cycler. To detect classical AZF microdeletions, the cycling program involved preliminary denaturation at $94^{\circ} \mathrm{C}$ for $6 \mathrm{~min}$, followed by 35 cycles each of denaturation at $94^{\circ} \mathrm{C}$ for $40 \mathrm{~s}$, annealing at $55^{\circ} \mathrm{C}$ for $45 \mathrm{~s}$, and elongation at $72^{\circ} \mathrm{C}$ for $60 \mathrm{~s}$, followed by a final extension step at $72^{\circ} \mathrm{C}$ for $8 \mathrm{~min}$ and cooling to $4^{\circ} \mathrm{C}$ until electrophoretic detection. To detect AZFc partial deletions, the same reaction mixture and volume were used with each primer set, but instead using the following PCR protocol: 6 min initial denaturation at $95^{\circ} \mathrm{C}$, followed by 35 cycles of $40 \mathrm{~s}$ at $95^{\circ} \mathrm{C}, 45 \mathrm{~s}$ at $58^{\circ} \mathrm{C}$, and $60 \mathrm{~s}$ at $68^{\circ} \mathrm{C}$, with a final extension step at $72^{\circ} \mathrm{C}$ for $10 \mathrm{~min}$.

Next, $4 \mu \mathrm{L}$ classical AZF reaction products were mixed with 6X loading buffer (1-2 $\mu \mathrm{L}$ ) and separated on 1.5\% agarose gel (BioWest, Quinton, Spain) containing ethidium bromide $(0.5 \mu \mathrm{g} / \mathrm{mL})$ at $80 \mathrm{~V}$ for $30 \mathrm{~min}$, and partial AZFc reaction products $(8 \mu \mathrm{L})$ were analyzed by electrophoresis on 3\% agarose gels (Biowest) at $120 \mathrm{~V}$ for $40 \mathrm{~min}$. In addition, a 100-bp DNA ladder was run concurrently with each electrophoretic run to confirm product size and the results were visualized and recorded using a gel image system (1600, Tannon, Shanghai, China).

\section{Statistical analysis}

Outcome variables (age, testicular volume, and reproductive hormone levels) for vertical transmission men with AZFc deletions were compared to those with de novo mutations using the Student $t$-test and the results are reported as means \pm standard deviation. Statistical analysis was carried out using SPSS 17.0 (SPSS, Inc. Chicago, IL, USA). Statistical significance was assessed at $\mathrm{P}<0.05$ and all reported $\mathrm{P}$ values were 2 -sided.

\section{RESULTS}

A total of 22 pedigrees were evaluated, including 2 with AZFa, 2 with AZFb, 1 with $\mathrm{AZFb}+\mathrm{c}, 13$ with complete AZFc, and 4 with partial AZFc deletions. The distribution of investigated STSs in the AZF region of all family members is shown in Table 1. All sons with $\mathrm{AZFa}, \mathrm{AZFb}$, and $\mathrm{AZFb}+\mathrm{c}$ were azoospermic and their fathers showed no $\mathrm{Y}$ chromosome microdeletions, and pulsing with 12 AZFc deletions under the same conditions, the de novo mutations rate was $77.27 \%(17 / 22)$. Vertical transmission was detected in families $5,11,13$, and 22 , and both the fathers and sons showed an identical microdeletion of the AZFc region. Furthermore, we found a de novo expansion of the $\mathrm{b} 2 / \mathrm{b} 3$ deletion in family 3, in which the father showed the b2/b3 deletion (absence of the STS sY1191 and the presence of other STSs), but the son showed a complete AZFc deletion, which was attributed to vertical transmission in our study; thus, the vertical transmission rate of Yq AZFc was $29.41 \%(5 / 17)$. 


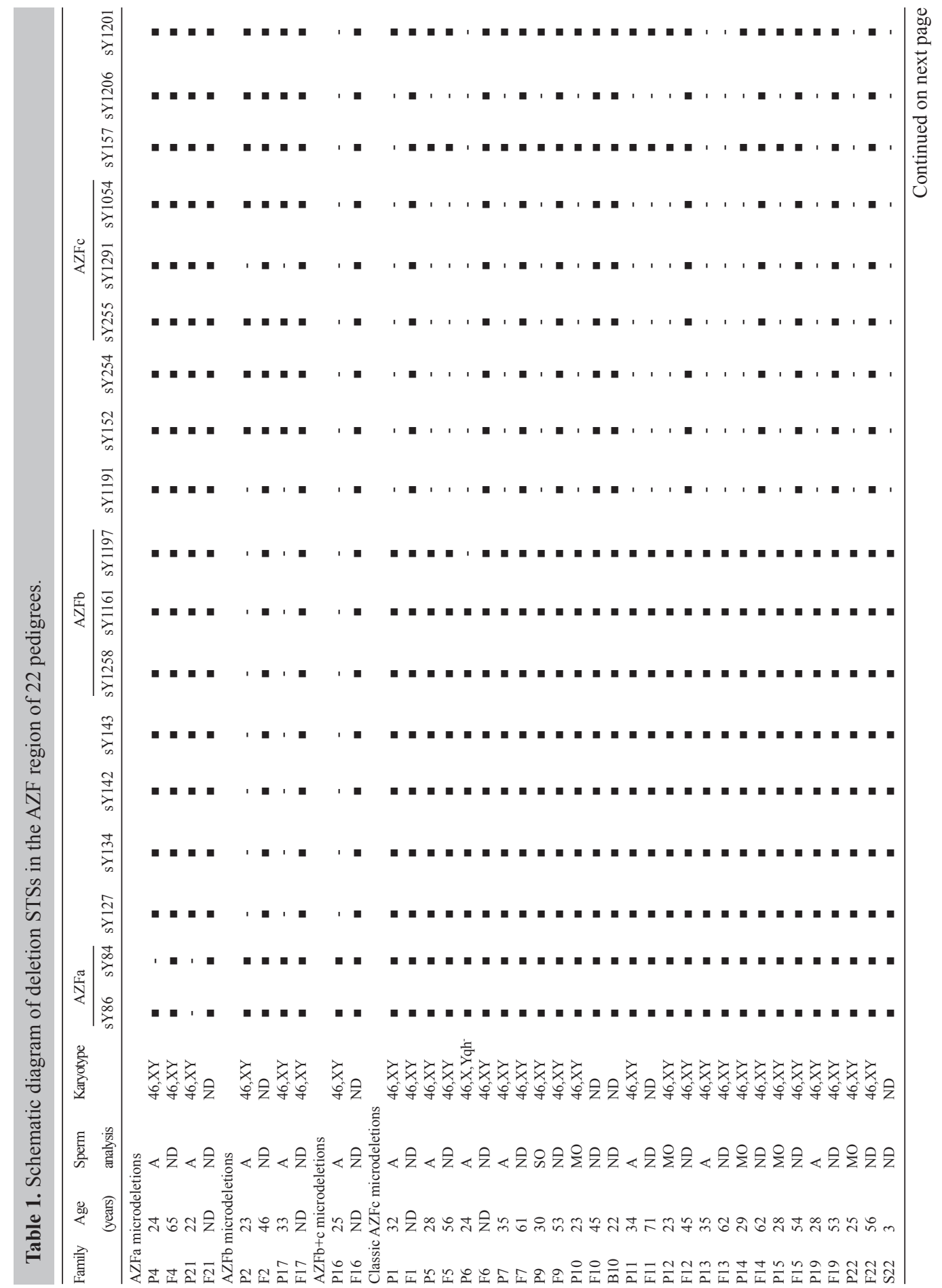




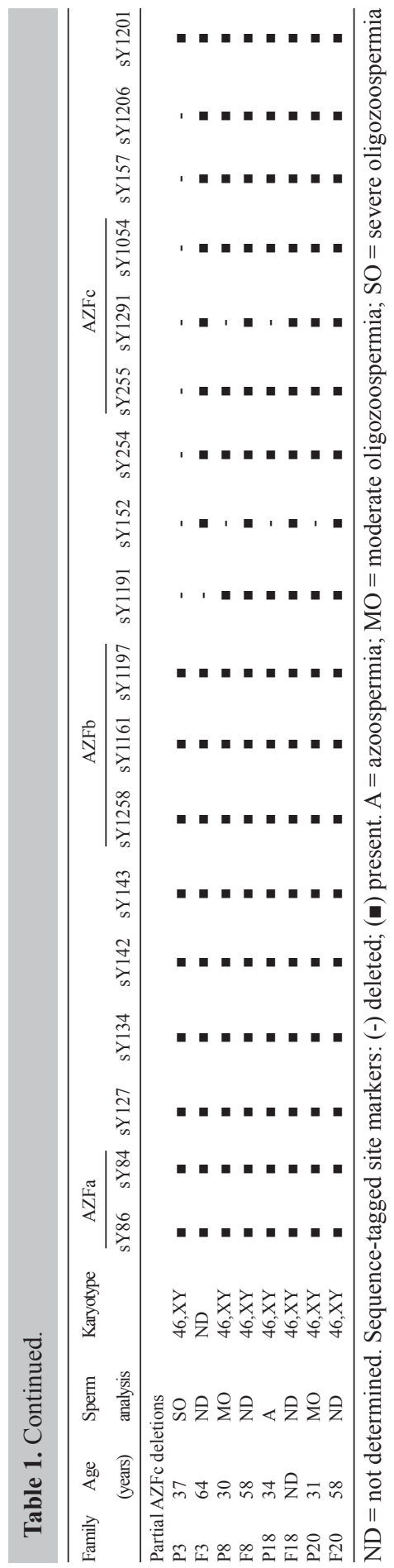


Karyotype analysis was available for 38 family members in this study. One proband with a complete AZFc deletion showed the 46, X, Yqh karyotype, while all others showed a normal karyotype $(46, \mathrm{XY})$. The clinical characteristics of patients and their male family members in 5 families showed transmission of the Yq AZFc microdeletion (Table 2). The probands of families 5, 11, and 13 were azoospermic and infertile for 2, 8, and 10 years, respectively. Probands 3 and 22 were severely oligozoospermic with sperm concentrations of $4.11 \times 10^{6}$ \% $\mathrm{mL}$ and $0.54 \times 10^{6} / \mathrm{mL}$, respectively. The proband with better semen quality was infertile for 10 years, while the other with poor sperm concentration fathered a son after 2 years. None of the patients had received any treatment, which may be attributed to genetic factors and family background. In addition, we found that the fertile subjects with AZFc deletions showed normal testicular volumes and normal sex hormone levels of FSH, LH, and T.

Table 2. Clinical data and reproductive outcome of individuals in families 3, 5, 11, 13, and 22 .

\begin{tabular}{|c|c|c|c|c|c|c|c|c|c|c|c|}
\hline & Individua & $\begin{array}{l}1 \text { Height } \\
(\mathrm{cm})\end{array}$ & $\begin{array}{c}\text { Weight } \\
\text { (kg) }\end{array}$ & $\begin{array}{l}\text { Sperm } \\
\text { concentration } \\
\left(\times 10^{6} / \mathrm{mL}\right)\end{array}$ & $\begin{array}{l}\text { Testis size } \\
\mathrm{L} / \mathrm{R}(\mathrm{mL})\end{array}$ & $\begin{array}{c}\text { PRL } \\
(86-324 \\
\mu \mathrm{IU} / \mathrm{mL})^{\mathrm{a}}\end{array}$ & $\begin{array}{c}\text { FSH } \\
(1.5-12.4 \\
\mathrm{mIU} / \mathrm{mL})^{\mathrm{a}}\end{array}$ & $\begin{array}{c}\mathrm{LH} \\
(1.7-8.6 \\
\mathrm{mIU} / \mathrm{mL})^{\mathrm{a}}\end{array}$ & $\begin{array}{c}\text { Testosterone } \\
(9.9-27.8 \\
\left.)^{\mathrm{a}} \quad \mathrm{nM}\right)^{\mathrm{a}}\end{array}$ & $\begin{array}{c}\text { Oestradiol } \\
(7.63-42.6 \\
\mathrm{pg} / \mathrm{ml})^{\mathrm{a}}\end{array}$ & Reproductive outcome \\
\hline \multirow[t]{2}{*}{ F-3 } & Proband & 170 & 69 & 4.11 & $12 / 12$ & 186.2 & 15.44 & 11.44 & 7.32 & 29.64 & $\begin{array}{l}\text { No treatment and infertility } \\
\text { for } 10 \text { years }\end{array}$ \\
\hline & Father & 165 & 55 & ND & $15 / 15$ & 156 & 10.1 & 8.1 & 22.55 & 25.4 & Fathered a son at 36 years old \\
\hline \multirow[t]{2}{*}{ F-5 } & Proband & 168 & 75 & 0 & $12 / 12$ & 369 & 14.4 & 7.5 & 12.4 & 20.42 & $\begin{array}{l}\text { No treatment and infertility } \\
\text { for } 10 \text { years }\end{array}$ \\
\hline & Father & 157 & 60 & ND & $18 / 18$ & 152.7 & 9.9 & 8.17 & 20.26 & 29.93 & Fathered a son at 29 years old \\
\hline \multirow[t]{2}{*}{ F-11 } & Proband & 170 & 65 & 0 & $12 / 12$ & 274.7 & 11.28 & 3.43 & 27.2 & 34.87 & $\begin{array}{l}\text { No treatment and infertility } \\
\text { for } 8 \text { years }\end{array}$ \\
\hline & Father & 171 & 62 & ND & $15 / 15$ & 152.4 & 8.6 & 8.3 & 23.4 & 27.64 & Fathered a son at 37 years old \\
\hline \multirow[t]{2}{*}{ F-13 } & Proband & 168 & 48 & 0 & $10 / 10$ & 331.4 & 12.08 & 3.49 & 9.72 & 27.04 & $\begin{array}{l}\text { No treatment and infertility } \\
\text { for } 2 \text { years }\end{array}$ \\
\hline & Father & 168 & 54 & ND & $12 / 12$ & 146.7 & 10.1 & 7.6 & 20.6 & 28.7 & Fathered a son at 27 years old \\
\hline \multirow[t]{3}{*}{ F-22 } & Proband & 175 & 70 & 0.54 & $15 / 15$ & 400 & 5.2 & 7.6 & 13.88 & 70 & $\begin{array}{l}\text { Infertility for } 3 \text { years, } \\
\text { Fathered a son at } 23 \text { years old }\end{array}$ \\
\hline & Father & 173 & 65 & ND & $15 / 15$ & 153.6 & 8.7 & 7.5 & 21.52 & 27.8 & Fathered a son at 32 years old \\
\hline & Son & 90 & 24 & ND & ND & ND & ND & ND & ND & ND & ND \\
\hline
\end{tabular}

$\mathrm{ND}=$ not determined; ${ }^{\text {Normal range. }}$

As shown in Table 3, age, testicular volume, and reproductive hormone levels, including prolactin, serum FSH, serum LH levels, serum T, and estradiol of men with verticaltransmitted AZFc deletions were compared with those of men with de novo AZFc deletions. The results revealed no statistical difference between the 2 groups. We excluded 1 patient from family 22 as he was still a boy and his clinical phenotype was not yet expressed.

Table 3. Correlation between age, testicular volume, and reproductive hormone levels in vertical transmission and de novo mutation men with AZFc deletions.

\begin{tabular}{|c|c|c|c|c|c|c|c|c|}
\hline & $\begin{array}{l}\text { Age } \\
\text { (years) }\end{array}$ & $\begin{array}{c}\text { Left } \\
\text { testicular } \\
\text { volume }(\mathrm{mL})\end{array}$ & $\begin{array}{c}\text { Right } \\
\text { testicular } \\
\text { volume }(\mathrm{mL})\end{array}$ & $\begin{array}{c}\text { PRL } \\
(86-324 \\
\mu \mathrm{IU} / \mathrm{mL})^{\mathrm{a}}\end{array}$ & $\begin{array}{c}\text { FSH } \\
(1.5-12.4 \\
\mathrm{mIU} / \mathrm{mL})^{\mathrm{a}}\end{array}$ & $\begin{array}{c}\mathrm{LH} \\
(1.7-8.6 \\
\mathrm{mIU} / \mathrm{mL})^{\mathrm{a}}\end{array}$ & $\begin{array}{c}\text { Testosterone } \\
(9.9-27.8 \\
n m o l / L)^{\mathrm{a}}\end{array}$ & $\begin{array}{c}\text { Oestradiol } \\
(7.63-42.6 \\
\mathrm{pg} / \mathrm{mL})^{\mathrm{a}}\end{array}$ \\
\hline $\begin{array}{l}\text { Vertical } \\
\text { transmission }(\mathrm{N}=4)\end{array}$ & $33.5 \pm 3.87$ & $11.5 \pm 1$ & $11.5 \pm 1$ & $290.33 \pm 79.5$ & $13.3 \pm 1.95$ & $6.47 \pm 3.82$ & $14.16 \pm 8.94$ & $27.99 \pm 6.01$ \\
\hline $\begin{array}{l}\text { De novo mutation } \\
(\mathrm{N}=13)\end{array}$ & $28 \pm 3.46$ & $12 \pm 5.76$ & $13.38 \pm 4.54$ & $246.04 \pm 123.6$ & $11.17 \pm 7.6$ & $7.74 \pm 3.47$ & $12.6 \pm 6.41$ & $24.86 \pm 10.42$ \\
\hline$P$ value & NS & NS & NS & NS & NS & NS & NS & NS \\
\hline
\end{tabular}

Values are reported as means $\pm \mathrm{SD}$. ${ }^{\mathrm{a}}$ Normal range; $\mathrm{NS}=$ not significant. 


\section{DISCUSSION}

The Yq-chromosome deletions are the most common cause of severe spermatogenetic defects (Ferlin et al., 2007). In our study of 22 pedigrees, 17 families were similar in which the probands showed AZF deletions, whereas their fathers and other paternal relatives did not. The mutation rate was $77.27 \%$, indicating that most $Y$ chromosome microdeletions are de novo mutations; these results agree with those of a previous study (Foresta et al., 2001). The Y chromosome is characterized by highly repetitive sequences (including direct repeats, inverted repeats, and palindromes) and high polymorphism. It has the lowest number of genes, but the highest copy number of repetitive sequences (Rozen et al., 2003) and homologous recombination, involving elimination of 1 repetitive sequence at the expense of another, which is thought to account for the random appearance of de novo AZF microdeletions in men (Repping et al., 2002).

In clinical terms, men with complete AZFc deletions show variable seminal and testicular phenotypes, with sperm production levels ranging from azoospermia to severe oligozoospermia (Vogt et al., 1996; Katagiri et al., 2004; Ferlin et al., 2007). However, in these patients, the presence of sperm in the ejaculate is a frequent event (in $50-60 \%$ of the cases), and natural conception is extremely rare because of low sperm counts (Kühnert et al., 2004; Xia et al., 2006). In our study of families 5, 11, 13, and 22, vertical transmission was detected, and both the fathers and sons showed classical AZFc microdeletions. These cases indicate that patients with full deletions of the AZFc region may also have the opportunity to procreate, but the son will inherit the deletions of his father with decreasing sperm quality. In addition, 1 type of Yq deletion can cause variant phenotypes in other individuals.

In family 3 , the proband showed expanded mutations of his father. The son showed a complete AZFc deletion, while his father lacked sY1191 (b2/b3 deletion). It has been reported that partial AZFc deletions are associated with an increased incidence of complete AZFc deletion in some instances (Zhang et al., 2007), which is also supported by results of this study. The expansion deletion may reflect a postzygotic mitotic error in the deletion of the father, and thus new deletions may occur during meiosis or early pre-implantation development; such deletions will be transmitted to the son (Lee et al., 2006). Although whether or not partial AZFc deletions, which are smaller than the complete AZFc deletion, affect spermatogenesis remains controversial (McElreavey et al., 2006), these deletions can be transmitted from a father to a son and may be expanded during such transmission, giving rise to de novo mutations.

Male fertility is reliant upon not only genes regulating the male germline but also genes in the networks responsible for developing the male gonads (Zhu et al., 2010). In the present study, we found that subjects (F3, F5, F11, F13, and P22) who showed AZFc deletions and were fertile presented special characteristics for the clinical phenotype, including normal testicular volumes ranging from $15-18 \mathrm{~mL}$, as well as normal sex hormone levels of FSH, LH, and T. This indicates the AZFc microdeletion is not a unique marker for infertility, and may be related to hormone levels, testicular volumes, age, semen concentration, and other impacts of the environmental and genetic backgrounds. Such consequences suggest that when screening for causes underlying idiopathic male infertility, it is necessary to consult with the patient's family members and investigate their family and ethnic backgrounds to determine their genetic risks. Our study has provided a theoretical and laboratory basis for genetic counseling of these patients.

PCR using primers for STS markers provides a simple and a rapid method for screening the AZF locus. The set of PCR primers was recommended by the the European Academy 
of Andrology (EAA) and the European Molecular Genetics Quality Network (EMQN) guidelines as the best choice for diagnosing AZF microdeletions, including sY14 (sex determining region on Y), zinc-finger X/ zinc-finger Y, sY84, sY86, sY127, sY134, sY254, and sY255. This primer set is sufficient for routine diagnostic use, enabling the detection of nearly all clinically relevant deletions and of over $95 \%$ of the deletions in the 3 AZF regions reported in previous studies (Zhu et al., 2010). In our study, we added sY143 (mapped to the distal of AZFb region), sY157 (mapped to the distal of AZFc region), and sY152 (located in the proximal site of the $D A Z$ gene) for classical AZF detection. In addition, we investigated the partial AZFc deletion to confirm its association with an increased risk of expansion of de novo mutation. It is necessary to screen additional STS markers of Yq to identify additional mutations in the Y chromosome and to clarify the correlation between genotype and phenotype.

In summary, our data showed that most $Y$ chromosome microdeletions result from de novo mutations via natural conception, particularly for $\mathrm{AZFa}, \mathrm{AZFb}$, and $\mathrm{AZFb}+\mathrm{c}$ deletions. Furthermore, men with Yq AZFc deletions show no obvious differences between vertical transmission and de novo mutation. It is possible that different Yq deletions exist in different families and have different effects on the fertility status of fathers and sons. The restriction of the associated phenotype with spermatogenic failure indicates the remarkable functional specialization of the regions affected of the Y chromosome.

\section{ACKNOWLEDGMENTS}

We are grateful to all of the family members who participated in the study. We are also grateful to all staff of the Andrology Laboratory for their excellent work. Research supported by the National Population and Family Planning Commission of P.R. China (\#2011-GJKJS-07).

\section{REFERENCES}

Briton-Jones C and Haines CJ (2000). Microdeletions on the long arm of the Y chromosome and their association with male-factor infertility. Hong Kong Med. J. 6: 184-189.

Eloualid A, Rhaissi H, Reguig A, Bounaceur S, et al. (2012). Association of spermatogenic failure with the b2/b3 partial AZFc deletion. PLoS One 7: e34902.

Ferlin A, Arredi B, Speltra E, Cazzadore C, et al. (2007). Molecular and clinical characterization of Y chromosome microdeletions in infertile men: a 10-year experience in Italy. J. Clin. Endocrinol. Metab. 92: 762-770.

Foresta C, Moro E and Ferlin A (2001). Y chromosome microdeletions and alterations of spermatogenesis. Endocr. Rev. 22: 226-239.

Gatta V, Raicu F, Ferlin A, Antonucci I, et al. (2010). Testis transcriptome analysis in male infertility: new insight on the pathogenesis of oligo-azoospermia in cases with and without AZFc microdeletion. BMC Genomics 11: 401.

Katagiri Y, Neri QV, Takeuchi T, Schlegel PN, et al. (2004). Y chromosome assessment and its implications for the development of ICSI children. Reprod. Biomed. Online 8: 307-318.

Krausz C, Quintana-Murci L and McElreavey K (2000). Prognostic value of Y deletion analysis: what is the clinical prognostic value of Y chromosome microdeletion analysis? Hum. Reprod. 15: 1431-1434.

Kühnert B, Gromoll J, Kostova E, Tschanter P, et al. (2004). Case report: natural transmission of an AZFc Y-chromosomal microdeletion from father to his sons. Hum. Reprod. 19: 886-888.

Lee SH, Ahn SY, Lee KW, Kwack K, et al. (2006). Intracytoplasmic sperm injection may lead to vertical transmission, expansion and de novo occurrence of Y-chromosome microdeletions in male fetuses. Fertil. Steril. 85: 1512-1515.

Mau Kai C, Juul A, McElreavey K, Ottesen AM, et al. (2008). Sons conceived by assisted reproduction techniques inherit deletions in the azoospermia factor (AZF) region of the Y chromosome and the DAZ gene copy number. Hum. Reprod. 23:1669-1678.

McElreavey K, Krausz C and Bishop CE (2000). The human Y chromosome and male infertility. Results Probl. Cell Differ. 28: 211-232. 
McElreavey K, Ravel C, Chantot-Bastaraud S and Siffroi JP (2006). Y chromosome variants and male reproductive function. Int. J. Androl. 29: 298-303.

Repping S, Skaletsky H, Lange J, Silber S, et al. (2002). Recombination between palindromes P5 to P1 on the human Y chromosome causes massive deletions and spermatogenic failure. Am. J. Hum. Genet. 71: 906-922.

Rodovalho RG, Arruda JT and Moura KK (2008). Tracking microdeletions of the AZF region in a patrilineal line of infertile men. Genet. Mol. Res. 7: 614-622.

Rozen S, Skaletsky H, Marszalek JD, Minx PJ, et al. (2003). Abundant gene conversion between arms of palindromes in human and ape Y chromosomes. Nature 423: 873-876.

Stuppia L, Gatta V, Calabrese G, Guanciali Franchi P, et al. (1998). A quarter of men with idiopathic oligo-azoospermia display chromosomal abnormalities and microdeletions of different types in interval 6 of Yq11. Hum. Genet. 102: 566-570.

Shaffer LG, Slovak ML and Campbel LJ (2009). ISCN 2009: an international system for human cytogenetic nomenclature. Basel, Unionville, CT, pp. 53-54.

Vogt PH, Edelmann A, Kirsch S, Henegariu O, et al. (1996). Human Y chromosome azoospermia factors (AZF) mapped to different subregions in Yq11. Hum. Mol. Genet. 5: 933-943.

World Health Organization (1999). WHO laboratory manual for the examination of human semen and sperm-cervical mucus interaction, 4th edn. Cambridge University Press, Cambridge, UK.

Xia XY, Cui YX, Pan LJ, Hao LJ, et al. (2006). Analysis of an AZFc deletion family with natural transmission. Zhonghua Nan Ke Xue 12: 720-722.

Zhang F, Lu C, Li Z, Xie P, et al. (2007). Partial deletions are associated with an increased risk of complete deletion in AZFc: a new insight into the role of partial AZFc deletions in male infertility. J. Med. Genet. 44: 437-444.

Zhu XB, Liu YL, Zhang W, Ping P, et al. (2010). Vertical transmission of the Yq AZFc microdeletion from father to son over two or three generations in infertile Han Chinese families. Asian J. Androl. 12: 240-246. 